\title{
Cirandeiras: Desafios e Possibilidades
}

\author{
Larissa Oliveira Santos ${ }^{1}$; Érika Porto Grisi ${ }^{2}$
}

Resumo: A Humanização do parto vem sendo debatida constantemente e ganhando importância em rodas de discussão. Nesta perspectiva, a presente pesquisa teve como objetivo geral evidenciar os benefícios do parto humanizado através das ações do Grupo Cirandeiras de Vitória da Conquista - BA. Foi utilizada a metodologia descritiva exploratória, de natureza qualitativa. O Grupo Cirandeiras é um grupo de apoio às gestantes e seus parceiros o qual os auxiliam durante a gestação, parto e pós parto. Com encontros quinzenais, o grupo tem como benefício o apoio às gestantes e parceiros, assim como o encorajamento ao parto humanizado. Após participar de encontros e analisar entrevistas, foi notória a satisfação em relação ao grupo, pois os benefícios vão desde tirar dúvidas e medos até o empoderamento em relação ao protagonismo no parto.

Palavras-Chave: Humanização, Benefícios, Parto, Cirandeiras, Empoderamento.

\section{Cirandeiras: Challenges and Possibilities}

\begin{abstract}
The Humanization of childbirth has been constantly debated and gaining importance in discussion wheels. In this perspective, the present research had as general objective evidence the benefits of the humanized birth through the actions of the Group Cirandeiras of Vitória da Conquista - BA. The exploratory descriptive methodology was used, of a qualitative nature. The Cirandeiras Group is a support group for pregnant women and their partners who help them during pregnancy, delivery and postpartum. With fortnightly meetings, the group has the benefit of supporting pregnant women and partners, as well as encouraging humanized childbirth. After participating in meetings and analyzing interviews, satisfaction was evident in relation to the group, since the benefits range from doubts and fears to empowerment in relation to protagonism in childbirth.
\end{abstract}

Keywords: Humanization, Benefits, Childbirth, Cirandeiras, Empowerment.

\section{Introdução}

De acordo o Programa de Humanização no Pré-natal e Nascimento (2002) foram instituídos pelo Ministério da Saúde através da Portaria/GM n ${ }^{\circ}$ 569, de 1/6/2000, subsidiado nas análises das necessidades de atenção específica à gestante, ao recém-nascido e à mãe no período pós-parto, considerando como prioridades: concentrar esforços no sentido de reduzir as altas taxas de morbimortalidade materna, Peri e Neonatal registradas no país; adotar medidas que assegurem a melhoria do acesso, da cobertura e da qualidade do acompanhamento prénatal, da assistência ao parto, puerpério e neonatal.

\footnotetext{
${ }^{1}$ Faculdade Independente do Nordeste (FAINOR). Autor correspondente: los.oliveirasl@gmail.com

${ }^{2}$ Mestre em Psicologia Social pelo Programa de Pós Graduação em Psicologia Social da Universidade Federal de Sergipe - UFS. Professora de psicologia da Faculdade Independente do Nordeste - FAINOR
} 
A humanização do parto não começa no momento do nascimento, e sim quando se descobre a gestação, através de um acompanhamento humanizado. Segundo o Ministério da Saúde, o Programa de Humanização no Pré-natal e Nascimento estão estruturados a partir dos seguintes princípios: "Toda gestante tem direito ao acesso a atendimento digno e de qualidade no decorrer da gestação, parto e puerpério; toda gestante tem direito de saber e ter assegurado o acesso à maternidade em que será atendida no momento do parto; toda gestante tem direito à assistência ao parto e ao puerpério e que esta seja realizada de forma humanizada e segura, de acordo com os princípios gerais e condições estabelecidas na prática médica; todo recémnascido tem direito à assistência neonatal de forma humanizada e segura" (BRASIL, 2002).

Grande é a diferença entre o parto normal e o parto humanizado, o qual não envolve apenas a adequação do ambiente, mas também a maneira como a parturiente é tratada. Num artigo publicado pela revista MidwiferyToday em 2007, a norte-americana Robbie Davis-Floyd constata que hospitais da América Latina se declaram humanizados porque permitem que os pais participem do nascimento, e que existem dois tipos de humanização: o que ela chama de humanização superficial e a humanização profunda. A humanização superficial acontece quando a mãe é educadamente tratada e o quarto é bem estruturado para o parto, mas as intervenções não diminuem, enquanto que na humanização profunda pode-se não ter uma estrutura adequada disponível para a parturiente, porém a fisiologia do nascimento é respeitada.

Há também uma pequena diferença entre o parto normal e o parto natural. $\mathrm{O}$ parto normal atualmente vem acontecendo de forma bastante intervencionista onde a mulher fica em uma sala junto a outras, sem privacidade alguma, sem acompanhamento dos familiares e muitas vezes sendo mal tratadas. Alguns procedimentos considerados violência obstétrica são utilizados de forma rotineira como: corte vaginal (episiotomoia), uso de medicações para indução do parto, raspagem dos pelos pubianos, suspensão da alimentação, repouso na cama hospitalar e proibição da presença de um acompanhante. Já no parto natural a equipe acompanha a parturiente e realiza apenas as intervenções que são realmente necessárias. (RECIFE, 2015)

$\mathrm{O}$ parto tem se tornado um ato médico, onde o profissional costuma fazer o papel principal, uma vez que estudou para isso e a mãe assume apenas um papel coadjuvante no processo. A falta de informação sobre o assunto faz com que as mulheres se sintam incapazes de ter um parto natural e muitas se deixam levar pela vontade do obstetra e facilidade da cirurgia 
- a mãe que antes era protagonista do seu parto cede espaço para os cirurgiões. A humanização tem entre seus objetivos empoderar a mulher, garantir que a mesma tenha seus desejos respeitados e informá-la para que possa fazer suas próprias escolhas. Essa humanização deve começar ainda no pré-natal (BRASIL, 2014).

A cesariana se tornou um dos procedimentos mais comuns no Brasil, é uma via de parto cirúrgica que deveria ser utilizada apenas em casos onde a mãe e/ou o bebê correm algum risco. São realizados cortes (abdômen e útero) para retirada do bebê e considerando que o corte é uma intervenção cirúrgica, há a necessidade de anestesias, suturas, medicamentos e também uma recuperação mais demorada onde em alguns casos pode ocorrer infecção (PINHEIRO, 2015).

A indicação desnecessária de cesariana cresce e são muitas as falsas indicações que são alegadas para desencorajar a mãe a ter seu filho de maneira natural. A médica obstetra Melania Amorim e a obstetriz Ana Cristina Duarte, organizaram uma lista com falsas e reais indicações. Algumas das falsas indicações citadas por elas são: adolescência; idade materna avançada; circular de cordão; cegueira materna; bebê muito grande ou muito pequeno; cesária anterior e várias outras indicações. Ainda segundo Amorim e Duarte (2016), em alguns momentos a cesariana é realmente indicada, como no caso de Prolapso de cordão com dilatação não completa; descolamento prematuro da placenta com feto vivo fora do período expulsivo; placenta prévia parcial ou total (total ou centro-parcial); apresentação córmica (situação transversa) durante o trabalho de parto (antes pode ser tentada a versão); ruptura de vasa prévia.

No Brasil muitos são os projetos que tentam resgatar a humanização do parto, um deles é o projeto Cirandeiras, em Vitoria da Conquista - Bahia com o apoio ao parto humanizado e maternidade ativa, que visa a melhor qualidade do nascimento. O grupo é composto por doulas, enfermeiras, psicólogas, obstetras e acima de tudo por mulheres que buscam a liberdade de sentir a emoção de ter seu filho de maneira natural, sem intervenções médicas desnecessárias, muitas vezes no ambiente de sua casa, rodeada de atenção, carinho e amor, deixando-a confortável para protagonizar uma fase importante da vida de uma mulher.

Realizando encontros quinzenais em uma Universidade Federal da cidade, as idealizadoras do grupo orientam as gestante sobre vários assuntos que são direcionados não somente a mãe, mas também a seu companheiro e demais familiares, bem como a troca de informações entre as participantes. 
Nesta perspectiva, este estudo teve por objetivo geral: Conhecer sobre o Grupo Cirandeiras e sua atuação no município de Vitoria da Conquista - Bahia. E como objetivos específicos: descrever as principais ações do Grupo Cirandeiras; analisar a atuação do grupo destacando os desafios e possibilidades dos serviços prestados as parturientes do pré-natal e pós parto; e coletar depoimentos de mulheres que tiveram filhos antes e/ou depois de conhecer o grupo.

\section{Metodologia}

Trata-se de uma pesquisa exploratório-descritiva que de acordo Lakatos e Marconi (2003) é uma investigação de pesquisa prática com a formulação de questões ou problema com finalidade de permitir uma maior familiaridade entre o pesquisador e o tema pesquisado e tem como objetivo descrever determinado fenômeno e podem ser encontradas tanto descrições quantitativas quanto qualitativas. Também será usada na coleta de material a pesquisa bibliográfica que segundo Lakatos e Marconi (2001), citado por Oliveira (2011), é considerada toda fonte de coleta de dados secundárias, abrangendo toda bibliografia, desde publicações, jornais, revistas, sites, filmes, documentários entre outras, que tenha como finalidade colocar o pesquisador em contato com tudo que foi dito sobre o assunto.

Quanto à natureza é de abordagem qualitativa, desta maneira o contato direto com o campo a ser avaliado será o mesmo como fonte para análise. Moresi (2003) aponta que a pesquisa qualitativa deve ser usada para entender o porquê do individuo fazer tal coisa, ajudando assim compreender a importância do assunto estudado.

A pesquisa foi realizada através da participação das rodas de encontro do grupo Cirandeiras em uma cidade no interior da Bahia. Participaram da pesquisa, mulheres presentes na roda de encontro e que estavam dispostas a relatar sobre sua experiência em relação ao parto, seja ele humanizado ou não. Os critérios de inclusão foram mulheres com idade acima de 18 anos que tiveram filhos antes e/ou após conhecer o grupo. Os critérios de exclusão foram mulheres que não tiveram filhos e menores de 18 anos.

A coleta de dados foi norteada por entrevista e observação, onde, no momento do encontro, foram cedidos relatos de experiências das participantes. A coleta foi realizada em dois 
encontros, onde um foi usado para observação e entrega do questionário e outro para devolução do mesmo já preenchido.

Os relatos que compõem o material de análise dessa pesquisa são de mulheres que tiveram partos antes e/ou depois de participarem do grupo, buscando observar através deles a percepção das mesmas em relação ao parto humanizado e não humanizado, independente da via de nascimento do bebê ter sido vaginal ou abdominal.

Os dados foram analisados por meio exploratório descritivo, a fim de gerar uma discussão qualitativa em relação ao Grupo Cirandeiras. A pesquisa foi realizada após aprovação do Comitê de Ética, em consonância com os preceitos éticos da Resolução no 466/12 do Conselho Nacional de Saúde (CNS).

\section{Resultados e Discussões}

\section{População participante}

A população estudada foi composta por dez mulheres que contemplam o objetivo geral do estudo, sendo que duas delas estão esperando seu segundo filho. Os encontros intitulados como "Roda" acontecem quinzenalmente num espaço de aulas de uma universidade do interior da Bahia e são frequentadas por mulheres gestantes ou não, por seus parceiros e alguns visitantes. $\mathrm{O}$ grupo tem intuito de empoderar mulheres para protagonizarem seu próprio parto.

Como forma de privacidade, as participantes na pesquisas serão identificadas como Cirandeiras $n$.

\section{Aspectos negativos e positivos}

Após participar das rodas foi possível compreender a magnitude e riqueza dos assuntos discutidos, bem como apreender os propósitos do grupo. A análise das entrevistas se deu de maneira exploratória, tendo como visão fatores que contribuem para a ocorrência de determinados elementos. (VERGARA, 2007). Com isso, foram identificados muitos benefícios relacionados ao grupo Cirandeiras contra nenhum ponto negativo associado ao mesmo, embora 
tenham sido identificados pontos negativos vinculados ao parto não humanizado, independendo da via (vaginal, por exemplo).

Alguns dos pontos negativos identificados no parto não humanizado foram: intervenções inadequadas, violência obstétrica e falta de preparo da equipe, conforme é possível perceber nas falas apresentadas abaixo:

"O parto fora do Cirandeiras foi normal, porém, cheio de intervenções e violência obstétrica [...]" Cirandeira 1.

"Meu parto fora do Cirandeiras foi por via cesária, onde tive uma equipe despreparada a qual não me acolheu bem e fizeram manobras que fazendo parte do grupo pude ver que foi 'desnecessária'." Cirandeira 4.

"Tive meu parto por via vaginal com fórceps, fui recebida em uma determinada unidade hospitalar com falta de educação, além de um corte em minha vagina que levou alguns pontos. Isso me fez buscar apoio na roda para tirar esse trauma e me encorajar na minha segunda gestação que está na reta final" Cirandeira 2.

Vemos então, que tanto no parto cirúrgico quanto no vaginal alguns fatores contribuíram para a percepção negativa dessas mulheres sobre seus partos o que estimulou a procura pelo grupo como forma de apoio.

Sabendo da importância do acolhimento não somente no momento do parto, mas em todos os momentos da gestação, o Grupo Cirandeiras está disposto a receber mulheres e seus companheiros para esclarecer dúvidas com intuito de preparar os pais para uma nova etapa da vida que é a chegada de um bebê, como se percebe nas falas abaixo:

"O Cirandeiras foi muito importante no meu processo gestacional, até o trabalho de parto, por meio do grupo eи е теu esposo podemos compreender melhor o assunto, vivenciar as múltiplas experiências compartilhadas e assim nos apresentar mais calmos e empoderados no dia do parto [...]. " Cirandeira 3

Os fatores positivos do grupo são inúmeros, sendo que a maioria das entrevistadas relatou que recebem informação de qualidade e partilham suas experiências, o que pode ser confirmado nas falas a seguir:

"[...] Não consigo ver a parte negativa de estar em uma roda, desde que essa tenha a proposta de acolhimento." Cirandeira 5

"[...] Não vejo nenhum aspecto negativo no grupo de apoio, apenas positivos, sobretudo possibilidade para as mães compartilharem suas angustias sem serem julgadas. " Cirandeira 6 
Portanto, o grupo não somente encorajam as gestantes para o nascimento do bebê, mas, as acolhem sem julgamentos, tornando o grupo uma rede acolhimento e apoio antes e depois do parto.

\section{Benefícios do Grupo Cirandeiras}

É notória a satisfação quanto ao acolhimento do grupo tanto às mães, quanto aos parceiros e visitantes. Desta forma, vários são os benefícios apontados pelas participantes, tais como, oportunidade de dialogar, desabafar sem medo de julgamentos, além do empoderamento, o que pode ser constatado nas falas abaixo:

\footnotetext{
"Encontrar pessoas com as mesmas histórias é importante, acolhedor, pois por mais que existam outras redes, a roda é um espaço que oportuniza falar sobre dúvidas que comumente não é dito em outros espaços. " Cirandeira 5

"Acolhimento, informação, preparação, dialogo, espaço de dúvidas, angústias, desabafos e comemorações. Com o Cirandeiras, as gestantes e também os parceiros, têm acesso a informação de qualidade, facilitando escolhas esclarecidas e o empoderamento" Cirandeira 7

"Acho que o grande beneficio é ser um espaço onde as mulheres ouvem e falam sem medo de serem julgadas ou desencorajadas. Acabamos encontrando ressonância dos nossos desejos. Isso é importante na construção do encorajamento e empoderamento para o parto e a maternidade" Cirandeira 8
}

\section{Desafios}

Pode-se notar os benefícios do grupo, mas como todos os grupos independentes, existem alguns desafios e o que predomina é ainda o preconceito de algumas mães não participantes em relação à humanização do parto, seja por medo ou desencorajamento, segundo falas a seguir:

"[...] Falta iniciativa das mulheres em geral, em querer fazer parte do próprio parto. Estamos numa geração de mulheres em que a tecnologia tomou conta do nascimento" Cirandeira 10 
[...] "Já me falaram que sou louca por querer meu parto humanizado. No grupo me sinto empoderada e isso me tornou mais segura em relação ao que quero. Algumas amigas não querem nem conhecer o grupo, dizem que parto normal é coisa de velho, que hoje é parto modernizado e não humanizado" Cirandeira 9

É notória a busca das pessoas por mecanismos que facilitem o seu cotidiano nos dias atuais, e essa realidade não é diferente no âmbito da saúde. A tecnologia e seus avanços vêm ganhando cada vez mais espaço e algumas mulheres buscam por uma maior facilidade na hora do parto.

Seguindo essa lógica, muitos pais optam pela comodidade de poder escolher o dia e hora que seus filhos venham ao mundo através da via de parto abdominal, buscando com isso a diminuição da dor através da analgesia durante o nascimento, ainda que a recuperação da mulher seja mais lenta e dolorosa nesses casos.

Com isso o grupo tem um grande desafio que é o de resgatar a experiência do parto natural, onde o dia e hora do nascimento são determinados pelo bebê, apoiando as gestantes em suas escolhas e empoderando-as, através de informações, para que possam protagonizar o próprio parto.

\section{Conclusão}

Diante da fisiologia reprodutora da mulher e do universo feminino de ser mãe, percebese que ainda existe uma negligência às suas vontades no que concerne a escolha da via de parto, sendo que, muitas vezes são desconsideradas por conveniência médica e pela praticidade que o ato cirúrgico oferece. Dado as exceções, muitas vezes a informação é quase nula quanto aos tipos de partos durante acompanhamento individual da gestante.

Além disso, no momento do parto, além da possibilidade de acontecer intervenções desnecessárias e/ou um parto não ser bem assistido, as gestantes muitas vezes se encontram sem informação do que vai acontecer no momento do nascimento do bebê e de quais procedimentos podem ser opcionais. Dessa forma, a falta de conhecimento juntamente com a fragilidade do momento, acaba por conceder um poder e uma decisão médica, visto que a 
estatística de parto cirúrgico ultrapassa $50 \%$ dos nascimentos realizados no Brasil, fazendo dessa parcela das parturientes não adeptas ao parto natural.

Nos relatos coletados para este estudo, são poucos os obstetras que indicam o parto vaginal, justificando através de circular de cordão umbilical e até mesmo argumentando uma difícil passagem do bebê na hora do nascimento. Isto contribui consideravelmente para um possível desencorajamento e até mesmo, medo do momento e complicações do parto.

O grupo Cirandeiras por meio dessas dificuldades e relatos traz consigo a missão de acolher essas mulheres futuras mães ou não, bem como seus esposos, para sanar suas dúvidas, educar através da informação, assim como, encorajá-las a este momento tão importante na vida do casal.

Pós análise dos dados e participação nas rodas, é possível afirmar que algumas mulheres antes da presença no grupo, se limitam as condutas médicas e possuem um certo medo em relação ao parto natural. Surgem certos questionamentos como: "Irei dar conta do parto vaginal?" “Terei passagem?” "Qual a intensidade da dor?”. E os medos não acabam por aí, muitas mulheres referem angústia sobre a própria maternidade e como cuidar do seu bebê.

Com a participação nas rodas, essas dúvidas e medos são trabalhados de maneira simples, com uma linguagem clara e objetiva. A troca de experiências entre elas trazem informações válidas e um momento onde todas podem expressar sem demais julgamentos. Os benefícios estendem aos parceiros também, que além de obter informações se preparam para o nascimento e puerpério junto às grávidas, fazendo deste um momento conjugal e não mais exclusivo da mulher.

\section{Referências}

AMORIM E MELANIA, Disponível em: $<$ http://estudamelania.blogspot.com.br/2012/08/indicacoes-reais-e-ficticias-de.html $>$ Acesso em 22/04/2016

PINHEIRO, Pedro. Parto por cesariana, Vantagens e Riscos, 2015 disponível em: < http://www.mdsaude.com/2013/10/parto-cesariana.html >Acesso em: 22/04/2016 BENATTI, Luciana. Disponivel em <http://casamoara.com.br/normal-x-humanizado-vocesabe-mesmo-a-diferenca/\#more-2588>-- Acesso - 27/03/2016 
Davis-Floyd, Robbie.(2007), Mudando Parto: O Exemplo da América Latina (Tradução), 2007, Disponível em: <https://www.midwiferytoday.com/articles/latinamerica.asp>. Acesso em:27/03/2016

VERGARA, Sylvia Constant. Projetos e relatórios de pesquisa em administração. 9 ed. p.45 São Paulo: Atlas, 2007. Acesso em Maio de 2017

BRASIL. Ministério da Saúde. Humanização no pré-natal e nascimento; Brasília- DF 2002.Disponível em: http://bvsms.saude.gov.br/bvs/publicacoes/parto.pdf. Acesso em: mai., 2016.

Ministério da Saúde. Caderno HumaizaSus, Volume 4 - Humanização do Parto e do Nascimento; Brasilia- DF 2014. Disponível em: http://www.redehumanizasus.net/sites/default/files/caderno_humanizasus_v4_humanizacao_p arto.pdf. Acesso em: mai., 2016.

_. Ministério da Saúde. Humanização do parto. Nasce o respeito - Informações práticas sobre seus direitos. Recife 2015. Disponível em: http://www.mppe.mp.br/mppe/attachments/article/4240/cartilha\%20humanizacao\%20do\%20p arto\%20pdf.pdf. Acesso em: Maio 2017

Como citar este artigo (Formato ABNT):

SANTOS, Larissa O.; GRISI, Érika P. Cirandeiras: Desafios e Possibilidades. Id on Line Revista Multidisciplinar e de Psicologia, Maio de 2017, vol.11, n.35, p.441-450. ISSN: 1981-1179.

Recebido: 27.05.2017

Aceito: 29.05 .2017 